\title{
Entorhinal Cortex Thickness Predicts Cognitive Decline in Alzheimer's Disease
}

\author{
Latha Velayudhan ${ }^{\mathrm{a}, \mathrm{b}, *}$, Petroula Proitsi ${ }^{\mathrm{a}}$, Eric Westman ${ }^{\mathrm{c}}, \mathrm{J}-$ Sebastian Muehlboeck ${ }^{\mathrm{d}}$, Patrizia Mecocci ${ }^{\mathrm{e}}$, \\ Bruno Vellas $^{\mathrm{f}}$, Magda Tsolaki ${ }^{\mathrm{g}}$, Iwona Kłoszewska ${ }^{\mathrm{h}}$, Hilkka Soininen ${ }^{\mathrm{i}}$, Christian Spenger ${ }^{\mathrm{d}}$, \\ Angela Hodges ${ }^{\mathrm{a}}$, John Powell ${ }^{\mathrm{a}}$, Simon Lovestone ${ }^{\mathrm{a}}$, Andrew Simmons ${ }^{\mathrm{a}}$; \\ AddNeuroMed Consortium \\ ${ }^{a}$ King's College London, Institute of Psychiatry, London and NIHR Biomedical Research Centre for \\ Mental Health, London, UK \\ ${ }^{\mathrm{b}}$ Department of Health Sciences, University of Leicester, Leicester, UK \\ ${ }^{\mathrm{c}}$ Department of Neurobiology, Care Sciences and Society, Karolinska Institutet, Stockholm, Sweden \\ ${ }^{\mathrm{d}}$ Department of Clinical Science, Intervention and Technology, Karolinska Institutet, Stockholm, Sweden \\ ${ }^{\mathrm{e}}$ Institute of gerontology and Geriatrics, University of Perugia, Perugia, Italy \\ ${ }^{\mathrm{f}}$ INSERM U 558, University of Toulouse, Toulouse, France \\ g $3 r d$ Department of Neurology, Medical School, Aristotle University Thessaloniki, Thessaloniki, Greece \\ ${ }^{\mathrm{h}}$ Medical University of Lodz, Lodz, Poland \\ ${ }^{\mathrm{i}}$ Department of Neurology, University of Eastern Finland and Kuopio University Hospital, Kuopio, Finland
}

Accepted 27 August 2012

\begin{abstract}
Biomarkers for Alzheimer's disease (AD) based on non-invasive methods are highly desirable for diagnosis, disease progression, and monitoring therapeutics. We aimed to study the use of hippocampal volume, entorhinal cortex (ERC) thickness, and whole brain volume (WBV) as predictors of cognitive change in patients with AD. 120 AD subjects, 106 mild cognitive impairment (MCI), and 99 non demented controls (NDC) from the multi-center pan-European AddNeuroMed study underwent MRI scanning at baseline and clinical evaluations at quarterly follow-up up to 1 year. The rate of cognitive decline was estimated using cognitive outcomes, Mini-Mental State Examination (MMSE) and Alzheimer disease assessment scale-cognitive (ADAS$\operatorname{cog}$ ) by fitting a random intercept and slope model. AD subjects had smaller ERC thickness and hippocampal and WBV volumes compared to MCI and NDC subjects. Within the AD group, ERC $>$ WBV was significantly associated with baseline cognition (MMSE, ADAS-cog) and disease severity (Clinical Dementia Rating). Baseline ERC thickness was associated with both longitudinal MMSE and ADAS-cog score changes and WBV with ADAS-cog decline. These data indicate that AD subjects with thinner ERC had lower baseline cognitive scores, higher disease severity, and predicted greater subsequent cognitive decline at one year follow up. ERC is a region known to be affected early in the disease. Therefore, the rate of atrophy in this structure is expected to be higher since neurodegeneration begins earlier. Focusing on structural analyses that predict decline can identify those individuals at greatest risk for future cognitive loss. This may have potential for increasing the efficacy of early intervention.
\end{abstract}

Keywords: Alzheimer's disease, biomarker, cognitive decline, entorhinal cortex, hippocampus, whole brain volume

\section{INTRODUCTION}

\footnotetext{
${ }^{*}$ Correspondence to: Latha Velayudhan, Department of Old Age Psychiatry, King's College London, Institute of Psychiatry, De Crespigny Park, London, UK. Tel.: +44 41 2078480508; Fax: +44 41 2078480625; E-mails: latha.velayudhan@kcl.ac.uk; lv24@le.ac.uk.
} 
$[2,3]$. A range of neuroimaging techniques provide insight into AD-related neurodegeneration, including structural magnetic resonance imaging (MRI), positron emission tomography (PET), and functional MRI. Neuroimaging techniques can improve early detection and aid in identifying individuals at risk of developing AD. In particular, structural MRI has provided insight into the neuroanatomical profile of pre-clinical and early AD. MRI has demonstrated significant value in the prediction of conversion and disease progression [4].

From a neuropathological perspective, it has been suggested that the medial temporal lobe is the anatomical site of the first pathological alterations in $\operatorname{AD}[5,6]$. It has been shown that MRI is useful for detecting atrophy in the medial temporal structures affected early in the neurodegenerative process [4]. Decreased volumes of hippocampus and entorhinal cortex are connected to $\mathrm{AD}$ and to individuals at risk of developing the disease. It has been shown that atrophy of the medial temporal lobe can predict conversion in subjects in the prodromal stages of the disease, referred to as mild cognitive impairment (MCI) [4, 7-9]. Atrophy also correlates with memory impairment. Numerous studies have used baseline and serial MRI measures to predict future cognitive decline but mostly for conversion from MCI to $\mathrm{AD}$ [9-12], and there is need for assessing these MRI measures as potential markers of disease progression in $\mathrm{AD}$.

We have previously reported from the European Union AddNeuroMed multi-center MRI study that structural MRI measures discriminated AD from controls and MCI; and also demonstrated potential for prediction of conversion from MCI to AD [13-18]. The aims of the current study were to examine (a) the relationship between baseline hippocampal volume, entorhinal cortex thickness, and whole brain volume with baseline cognitive measures in (i) AD (ii) MCI, and (iii) age matched non-demented controls (NDC); and (b) to assess the associations of the baseline MRI measures with subsequent cognitive change over one year period. Our hypothesis was that smaller brain structures would be associated with worse baseline cognition and greater cognitive decline.

\section{METHODS}

\section{Participants and clinical assessment}

This study included data from 120 AD, 106 MCI, and 99 NDC participants from the AddNeu-
roMed study, a European Union funded FP6 program. AddNeuroMed is a longitudinal, multi-center study of biomarkers for AD [19]. All subjects underwent MRI scanning at baseline and cognitive testing at baseline and every 3 months up to one year.

Data was collected from six different sites across Europe: University of Kuopio, Finland; University of Perugia, Italy; Aristotle University of Thessaloniki, Greece; King's College London, United Kingdom; University of Lodz, Poland; and University of Toulouse, France. Written consent was obtained where the research participant had capacity, and in those cases where dementia compromised capacity, then assent from the patient and written consent from a relative, according to local law and process, was obtained. This study was approved by ethical review boards in each participating country. The inclusion and exclusion criteria were as follows.

\section{Alzheimer's disease \\ Inclusion criteria. Patients with probable mild to moderate AD (National Institute of Neurologi- cal and Communicative Disorders and Stroke and the Alzheimer's disease and Related Disorders Association [NINCDS-ADRDA] criteria) [20] and Mini-Mental State Examination (MMSE) [21] score range between 12 and 28, age 65 years or above.}

Exclusion criteria. Significant neurological or psychiatric illness, significant unstable systematic illness, or organ failure.

\section{Mild cognitive impairment}

Inclusion criteria. MMSE score range between 24 and 30, Clinical Dementia Rating (CDR) [22] scale score of 0.5 , Geriatric Depression Scale score less than or equal to 5 , age 65 years or above, medication stable, and good general health.

Exclusion criteria. Met the DSM- IV criteria for dementia, significant neurological or psychiatric illness, significant unstable systematic illness, or organ failure. The distinction between MCI and NDC was based on two criteria: $\mathrm{CDR}=0$ labeled the subject as control and $\mathrm{a} C D R=0.5$ labeled the subject as MCI. For the MCI subjects it was preferable that the subject and informant reported occurrence of memory problems.

\section{Non-demented control}

Inclusion criteria. MMSE score range between 24 and 30, $\mathrm{CDR}=0$, Geriatric Depression Scale score less 
than or equal to 5 , age 65 years or above, medication stable, and good general health.

Exclusion criteria. Met the DSM- IV criteria for dementia, significant neurological or psychiatric illness, significant unstable systematic illness, or organ failure.

The clinical assessment and cognitive testing of the AddNeuroMed subjects followed a standard protocol described previously [13, 23, 24]. Assessments included a structured interview including a detailed case and family history, Cambridge Examination for Mental Disorders of Older People (CAMDEX) [25]; cognitive testing with MMSE and Alzheimer disease assessment scale - Cognitive (ADAS-cog) [26] and stage of dementia with CDR sum of boxes score. The cognitive testing with ADAS-cog and MMSE were repeated every 3 months for a period of a year.

\section{Genotyping}

Venous blood was obtained for DNA extraction and genotyping for the apolipoprotein (APOE) alleles using standard methods [27]. The APOE haplotype (rs7412 and rs429358) was determined using two allelic discrimination assays based on fluorogenic $5^{\prime}$ nuclease activity: TaqMan single nucleotide polymorphism Genotyping Assays (Applied Biosystems,).

\section{Magnetic resonance imaging}

Data acquisition for the AddNeuroMed study was designed to be compatible with the Alzheimer Disease Neuroimaging Initiative (ADNI) [28]. The imaging protocol included a high resolution sagittal 3D T1-weighted MPRAGE volume (voxel size $1.1 \times 1.1 \times 1.2 \mathrm{~mm}^{3}$ ) and axial proton density/T2weighted fast spin echo images. The MPRAGE volume was acquired using a custom pulse sequence specifically designed for the ADNI study to ensure compatibility across scanners [28]. Full brain and skull coverage was required and detailed quality control was carried out on all MR images according to the AddNeuroMed quality control procedure [23, 29].

\section{Regional volume segmentation}

We applied the Freesurfer pipeline (version 4.5.0) to the MRI images to produce regional cortical thickness and subcortical volumetric measures. Cortical reconstruction and subcortical volumetric segmentation includes removal of non-brain tissue using a hybrid watershed/surface deformation procedure [30], automated Talairach transformation, segmentation of the subcortical white matter and deep grey matter volumetric structures (including hippocampus, amygdala, caudate, putamen, ventricles) [30-32], intensity normalization [33], tessellation of the grey matter white matter boundary, automated topology correction $[34,35]$, and surface deformation following intensity gradients to optimally place the grey/white and grey/cerebrospinal fluid borders at the location where the greatest shift in intensity defines the transition to the other tissue class [36-38]. Once the cortical models are complete, registration to a spherical atlas takes place which utilizes individual cortical folding patterns to match cortical geometry across subjects [39]. This is followed by parcellation of the cerebral cortex into units based on gyral and sulcal structure [40, 41]. This segmentation approach has been used for multivariate classification of $\mathrm{AD}$ and healthy controls [16, 17, 42, 72], neuropsychological-image analysis [15, 18], imaging-genetic analysis [43, 44], and biomarker discovery [24, 73, 74]. The current study focused on regional brain volumes and cortical thickness measures, specifically hippocampal volume, entorhinal cortex (ERC) thickness, and whole brain volume (WBV) which have been proposed to be related to $\mathrm{AD}$ and have received high level of attention in the recent literature $[4,7-12,16,17]$. Volumes from the left and the right hemisphere were averaged together. All volumetric measures from each subject were normalized by the subject's intracranial volume. Cortical thickness measures were not normalized and were used in their raw form [45].

\section{Statistical analysis}

Non-parametric and $t$-test analyses were used to test for differences in continuous outcomes such as MRI-based measures, cognition, severity measures, age, and education between AD, MCI, and NDC. The chi-square test was used to test for differences in categorical outcomes such as gender and the presence of the APOE $\varepsilon 4$ allele. Correlation analysis (Spearman non-parametric test) was used for associations between brain region volumes, cognitive scores (MMSE, ADAS-cog), and CDR for illness staging within the groups.

Rates of cognitive decline were determined by change in the cognitive measures (MMSE and ADASCog total scores). These measures were estimated by fitting a random intercept and slope model using xtmixed in STATA 10 (Stata Corporation, College 
Station, TX, USA). The average baseline cognitive outcome and the average change in the cognitive outcome over the follow-up time were calculated for all the AD patients, MCI, and NDC as a group (fixed effects). Subject-specific intercept and slope terms which reflected deviation from the group average (random effects) were also calculated. Follow-up time was defined as the number of years (days/365.25) passed since the baseline visit, and up to 5 time points (three months apart) was recorded for each patient. Time squared was also used to assess nonlinear cognitive decline.

Adjustment for age at baseline, education years, gender, cholinesterase inhibitors, center, and APOE genotype was made. Continuous outcomes were centered to their mean to aid interpretation of the model. As the main focus of the study was to study associations for cognitive decline in $\mathrm{AD}$, we did not differentiate MCI into converters and non-converters and used all MCI as a group.

An interaction between the MRI-based brain volumes and follow- up time (Entorhinal Cortex $\times$ TIME, Whole Brain $\times$ TIME, or Hippocampus $\times$ TIME) was used to test the null hypothesis that there was no difference in the rate of cognitive function, i.e., in slopes for different baseline brain volumes. The coefficient of the time variable in this case (TIME) would indicate the association between follow-up time with cognitive decline for average brain volume (since the variables are centered around their mean); the coefficient of the brain volume for each subject (Entorhinal Cortex, Whole Brain, or Hippocampus) would indicate the association of baseline brain volume with baseline cognitive assessment score and the coefficient of the interaction term (MRI brain volume $\times$ follow-up time) would indicate the effect of brain volume on cognitive decline over time. The results were based on using the brain measures as continuous variables and the quartiles for graphical view.

\section{RESULTS}

\section{Demographics, brain region, and baseline cognition}

The subject characteristics are shown in Table 1 . Predictably the AD patients had smaller regional brain measures and lower cognitive scores compared to agematched MCI and NDC subjects. Within AD subjects, ERC volumes correlated significantly with baseline MMSE $\left(p<0.01, r^{2}=0.3\right)$, ADAS-cog $(p<0.01$, $\left.r^{2}=-0.3\right)$, and CDR scores $\left(p<0.001, r^{2}=-0.3\right)$ and WBV with CDR $\left(p<0.001, r^{2}=-0.3\right)$. Within NDC, MMSE correlated with WBV $\left(p=0.02, r^{2}=-0.2\right)$ and with hippocampal volume ( $\left.p=0.04, r^{2}=-0.2\right)$. Within the MCI group, there were no significant correlations between MMSE and brain volumes.

\section{Brain region and longitudinal changes in cognition}

We did not identify any deviation from a linear cognitive decline model by including the TIME squared variable in the model (non-significant coefficient) and all the models therefore assumed a linear cognitive decline.

\section{Association of baseline ERC thickness with cognitive decline in $A D$ subjects}

Mixed effects models indicated a significant interaction between follow-up time measured with the

Table 1

Demographics and brain volumes between subjects with Alzheimer's disease (AD), mild cognitive impairment (MCI), and non-demented controls (NDC)

\begin{tabular}{|c|c|c|c|c|c|}
\hline & $\mathrm{AD}(n=120)$ & MCI $(n=106)$ & $\operatorname{NDC}(n=99)$ & $p<0.001^{* *}$ & $p<0.05^{* *}$ \\
\hline Gender (Female \%) & 64 & 49 & 53 & $\mathrm{NS}^{\mathrm{II}}$ & a \\
\hline Age in years & $74.82(6.21)$ & $74.00(5.64)$ & $74.56(5.14)$ & $\mathrm{NS}^{*}$ & \\
\hline Education & $7.91(4.01)$ & $9.03(4.18)$ & $10.67(4.89)$ & $b^{*}$ & $\mathrm{a}, \mathrm{c}$ \\
\hline APOE4 (\%) & 56 & 38 & 28 & $b^{\mathbb{T I}}$ & $\mathrm{a}$ \\
\hline MMSE & $20.83(4.83)$ & $27.21(1.64)$ & $28.96(1.28)$ & $\mathrm{a}, \mathrm{b}, \mathrm{c}^{*}$ & \\
\hline Hippocampus $\left(\mathrm{cm}^{3}\right)$ & $1.95(0.37)$ & $2.27(0.35)$ & $2.67(0.27)$ & $\mathrm{a}, \mathrm{b}, \mathrm{c}^{*}$ & \\
\hline$\%$ reduction to NDC & 27 & 15 & & & \\
\hline Entorhinal cortex (mm) & $2.62(0.53)$ & $3.00(0.36)$ & $3.24(0.36)$ & $a, b, c^{*}$ & \\
\hline$\%$ reduction to NDC & 19 & 7 & & & \\
\hline Whole brain volume & $0.82(0.04)$ & $0.85(0.03)$ & $0.85(0.03)$ & $\mathrm{a}, \mathrm{b}^{*}$ & \\
\hline$\%$ reduction to NDC & 4 & 0 & & & \\
\hline
\end{tabular}

Mean (SD); ${ }^{I I}$, chi-square; ${ }^{*}, t$-test; MMSE, Mini-Mental State Examination; APOE4, presence of at least one e4 allele. ${ }^{* *}$ Multiple comparisons abbreviated as: (a) AD subjects differ from subjects with MCI, (b) AD subjects differ from NDC subjects, (c) MCI subjects differ from NDC subjects. 
Table 2

Mixed effects regression for subjects with Alzheimer's disease (AD), non-demented control (NDC), and mild cognitive impairment (MCI) over one year, adjusted for age, gender, center, education, $\mathrm{APOE} \varepsilon 4$, and cholinesterase inhibitor therapy in $\mathrm{AD}$ group

\begin{tabular}{|c|c|c|c|c|c|c|c|c|c|c|c|c|c|}
\hline \multirow[t]{3}{*}{ Baseline brain area } & \multirow[t]{3}{*}{ Variable } & \multirow{2}{*}{\multicolumn{3}{|c|}{$\frac{\mathrm{AD}(n=120)}{\mathrm{MMSE}}$}} & \multirow{2}{*}{\multicolumn{3}{|c|}{ ADAS-cog }} & \multirow{2}{*}{\multicolumn{3}{|c|}{$\begin{array}{c}\text { NDC }(n=99) \\
\text { MMSE }\end{array}$}} & \multirow{2}{*}{\multicolumn{3}{|c|}{$\frac{\text { MCI }(n=106)}{\text { MMSE }}$}} \\
\hline & & & & & & & & & & & & & \\
\hline & & Beta & SE & $p$ & Beta & SE & $p$ & Beta & SE & $p$ & Beta & SE & $p$ \\
\hline \multirow[t]{3}{*}{ Entorhinal cortex } & Time (years) & -1.333 & 0.334 & $<0.001$ & 2.675 & 0.664 & $<0.001$ & -2.020 & 1.135 & 0.075 & -0.694 & 0.296 & 0.019 \\
\hline & Entorhinal cortex thickness & 2.661 & 0.755 & $<0.001$ & -5.083 & 1.555 & 0.001 & 0.157 & 0.361 & 0.665 & -0.036 & 0.341 & 0.916 \\
\hline & $\begin{array}{l}\text { Time (years) } \times \text { ERC } \\
\text { thickness }\end{array}$ & 1.705 & 0.648 & 0.009 & -5.737 & 1.282 & $<0.001$ & 0.002 & 0.001 & 0.094 & 0.234 & 0.586 & 0.689 \\
\hline \multirow[t]{3}{*}{ Whole brain volume } & Time (years) & -1.300 & 0.331 & 0.000 & 2.505 & 0.696 & 0.000 & -2.112 & 3.502 & 0.546 & -0.726 & 0.287 & 0.012 \\
\hline & Whole brain volume & 0.029 & 0.012 & 0.016 & -0.065 & 0.024 & 0.006 & 2.263 & 4.947 & 0.647 & 3.614 & 5.883 & 0.539 \\
\hline & Time (years) $\times$ WB volume & 0.018 & 0.009 & 0.049 & -0.052 & 0.019 & 0.007 & 0.006 & 0.011 & 0.575 & -0.197 & 8.471 & 0.981 \\
\hline \multirow[t]{3}{*}{ Hippocampus } & Time (years) & -1.322 & 0.336 & $<0.001$ & 2.574 & 0.710 & $<0.001$ & 0.942 & 1.245 & 0.449 & -0.633 & 0.287 & 0.028 \\
\hline & Hippocampal volume & 2.471 & 1.105 & 0.025 & -2.471 & 2.255 & 0.273 & 0.455 & 0.219 & 0.038 & 0.468 & 0.531 & 0.378 \\
\hline & Time $($ years $) \times$ Hippo & 0.219 & 0.906 & 0.809 & -2.509 & 1.912 & 0.189 & -0.001 & 0.001 & 0.391 & 0.015 & 0.854 & 0.986 \\
\hline
\end{tabular}

Coefficients of the interaction terms (brain measure $\times$ time) represented the influence of baseline brain measures on rates of change. Time (years) represents the association of follow-up time with cognitive decline for mean brain measures, and the respective brain measure coefficients represent the association of baseline measures with cognitive decline at baseline. MMSE, Mini-Mental State Examination; ADAS-cog, Alzheimer disease assessment scale-Cognitive. 


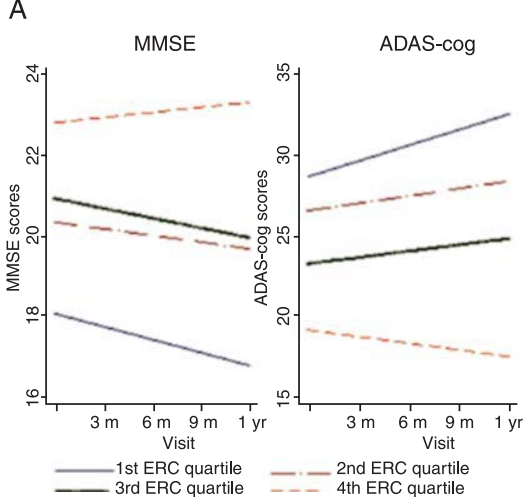

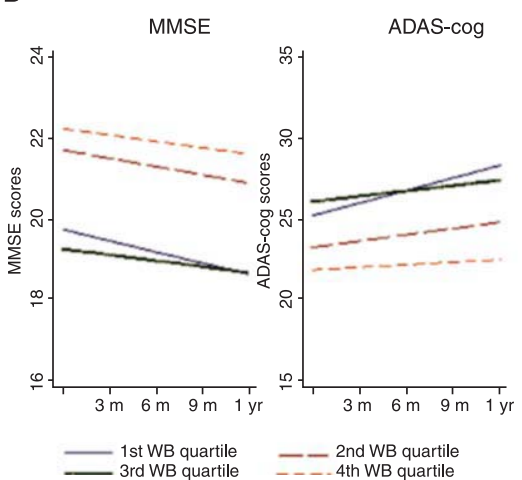

C

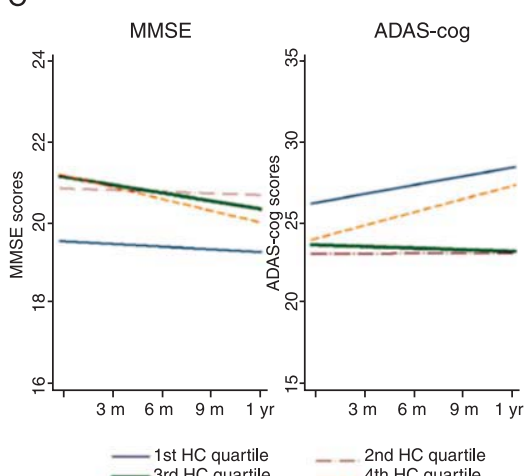

Fig. 1. Mini-Mental State Examination (MMSE) and Alzheimer disease assessment scale-Cognitive (ADAS-cog) decline over the quarterly visits for a year for Alzheimer's disease subjects in the four entorhinal cortex (ERC), whole brain volume (WBV), and hippocampus (HC) quartiles. MMSE score represents number of correct items; ADAS-cog score represent the number of errors. A) ERC thickness in mm [mean (SD)]: 1st ERC quartile: 1.97 (0.21); 2nd ERC quartile: 2.42 (0.10); 3rd ERC quartile: 2.83 (0.11); 4th ERC quartile: 3.31 (0.26). B) WBV divided by intracranial volume [mean (SD)]: 1st WBV quartile: 0.77 (0.02); 2nd WBV quartile: 0.81 (0.01); 3rd WBV quartile: 0.84 (0.01); 4th WBV quartile: 0.87 (0.02). C) HC volume in $\mathrm{cm}^{3}$ [mean (SD)] 1st HC quartile: 1.47 (0.17); 2nd HC quartile: 1.83 (0.09); 3rd HC quartile: 2.08 (0.06); 4th HC quartile: 2.40 (0.19).
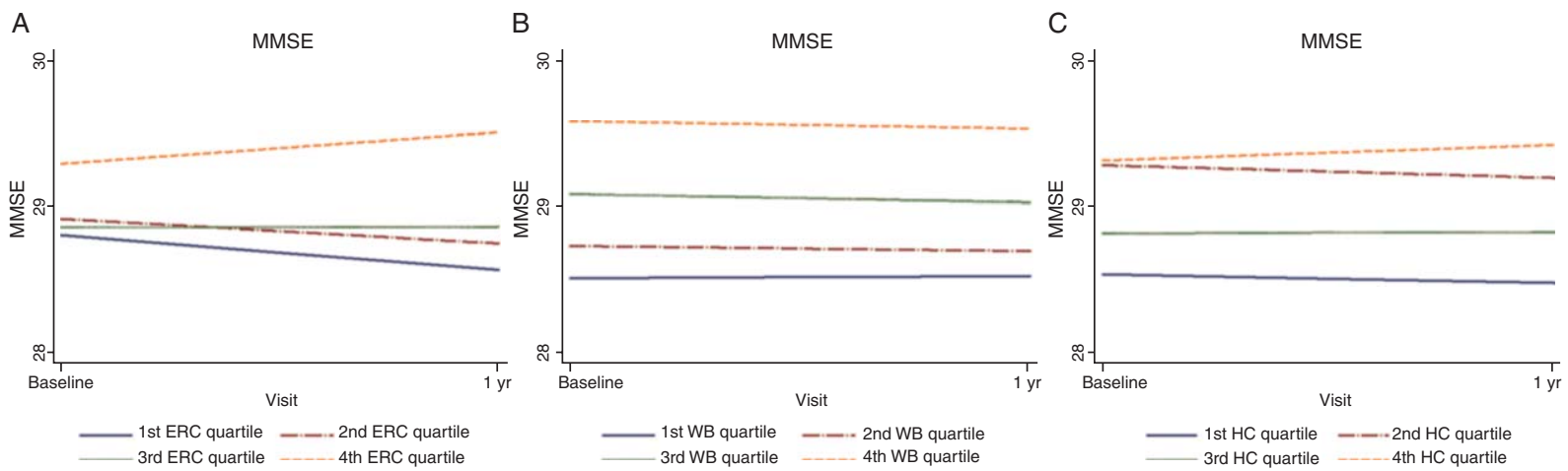

Fig. 2. Mini-Mental State Examination (MMSE) decline over 1 year for non-demented control subjects in the four entorhinal cortex (ERC), whole brain volume (WBV), and hippocampus (HC) quartiles showing no significant associations. MMSE score represents number of correct items. A) ERC thickness in mm [mean (SD)]: 1st ERC quartile: 2.76 (0.20); 2nd ERC quartile: 3.15 (0.07); 3rd ERC quartile: 3.37 (0.06); 4th ERC quartile: 3.67 (0.18). B) WBV divided by intracranial volume [mean (SD)]: 1st WBV quartile: 0.81 (0.02); 2nd WBV quartile: 0.85 (0.00); 3rd WBV quartile: 0.86 (0.01); 4th WBV quartile: 0.89 (0.01). C) HC volume in $\mathrm{cm}^{3}$ [mean (SD)]: 1st HC quartile: 2.31 (0.12); 2nd HC quartile: 2.58 (0.06); 3rd HC quartile: 2.78 (0.06); 4th HC quartile: 3.01 (0.12).

MMSE and ADAS-Cog and baseline ERC thickness ( $p=0.009$ and $p<0.001$, respectively) which indicated that baseline ERC thickness was related to the rate of cognitive decline measured with these two cognitive scales (Table 2).

Higher baseline ERC thickness was associated with slower cognitive decline measured with MMSE and ADAS-cog. In more detail, after adjusting for covariates, higher baseline ERC thickness in AD cases were associated with both higher baseline cognition measured with the MMSE and ADAS-cog measures (beta $=2.661(0.755), p<0.001$ and beta $=-5.083$
(1.55), $p=0.001$, respectively) and with slower cognitive decline, measured with MMSE (beta $=1.705$ (0.648), $p=0.009$ ) and ADAS-cog (beta $=-5.737$ (1.282), $p<0.001)$. To aid the interpretation, Fig. 1A displays the predicted MMSE and ADAS-cog slopes for the four baseline ERC thickness quartiles, highlighting the differences both in baseline cognitive scores but also in the rate of cognitive decline between different ERC quartiles, especially, for patients in the 4th quartile. For example, the expected average MMSE decline for patients in the lower ERC quartile was -2.34 per year $(p=0.001)$, whereas there was no 

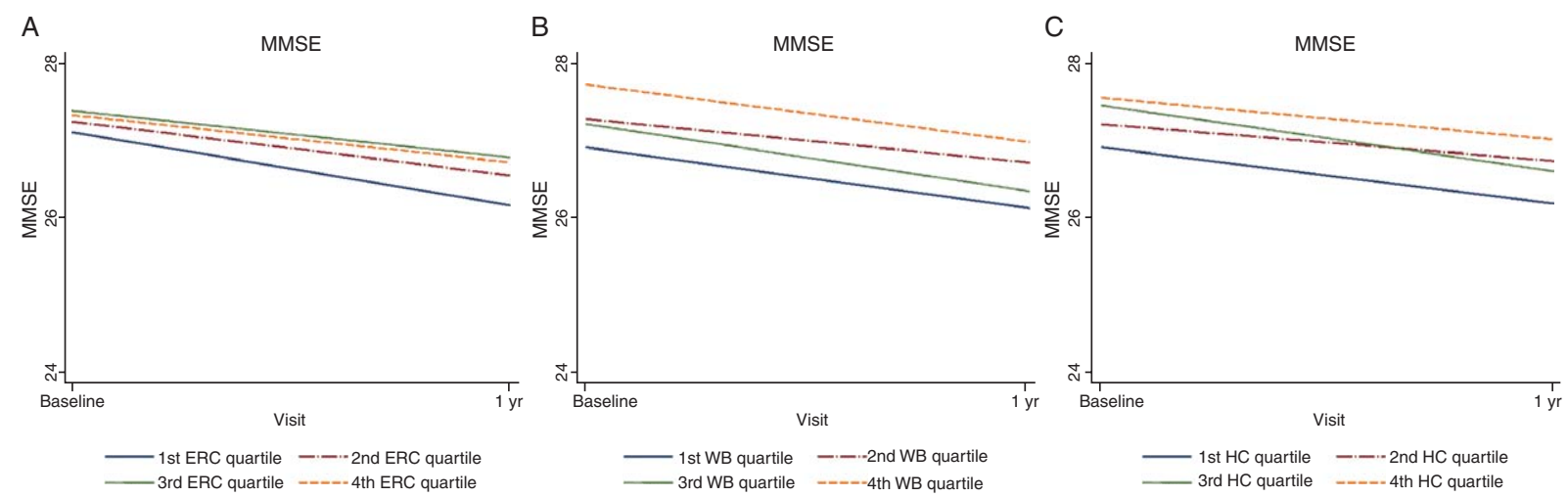

Fig. 3. Mini-Mental State Examination (MMSE) decline over 1 year for mild cognitive impairment subjects in the four entorhinal cortex (ERC), whole brain volume (WBV), and hippocampus (HC) quartiles showing no significant associations. MMSE score represents number of correct items. A) ERC thickness in mm [mean (SD)]: 1st ERC quartile: 2.30 (0.27); 2nd ERC quartile: 2.85 (0.14); 3rd ERC quartile: 3.25 (0.11); 4th ERC quartile: 3.62 (0.19). B) WBV divided by intracranial volume [mean (SD)]: 1st WBV quartile: 0.80 (0.02); 2nd WBV quartile: 0.84 (0.01); 3rd WBV quartile: $0.8(0.01)$; 4th WBV quartile: 0.89 (0.01). C) HC volume in $\mathrm{cm}^{3}$ [mean (SD)]: 1st HC quartile: 1.86 (0.18); $2 \mathrm{nd} \mathrm{HC} \mathrm{quartile:}$ 2.18 (0.05); 3rd HC quartile: 2.39 (0.07); 4th HC quartile: 2.72 (0.18).

significant decline for patients in the upper ERC quartile (beta $=0.372, p=0.557$ ). The same effect was observed for ADAS-Cog.

\section{Association of baseline WBV with cognitive decline in $A D$ subjects}

As in the case of ERC, mixed effect models indicated that baseline WBV was associated with higher baseline cognitive scores (MMSE beta $=0.028$ (0.012), $p=0.016$; ADAS-cog beta $=-0.065$ (0.024), $p=0.006)$ and also appeared to modify the rate of cognitive decline measured with MMSE and ADAS$\operatorname{cog}$, although the effect on MMSE measured decline was only marginal (Table 2). In more detail, baseline WBV appeared to have a strong influence on the rate of cognitive decline measured with ADAS-cog (beta $=-0.052(0.019), p=0.007$ ) and showed a modest effect on MMSE assessed decline (beta $=0.018$ (0.009), $p=0.049$ ). Lower baseline WBV predicted cognitive decline when assessed with the ADAS-cog and also to an extent with the MMSE (Fig. 1B, Table 2).

\section{Association of baseline hippocampal volume with cognitive decline in $A D$ subjects}

Finally, mixed effects models indicated that the baseline volume of the hippocampus was associated with baseline MMSE (beta $=2.471(1.105), p=0.025)$, i.e., patients with larger hippocampus volumes had higher MMSE (Table 2), but was not associated with baseline ADAS-cog scores, neither did it seem to modify the rate of cognitive decline assessed by the two cognitive tools (Fig. 1C, Table 2).

\section{Association of baseline ERC, WBV, and hippocampal volume with cognitive decline in NDC and MCI subjects}

Finally, mixed effects models indicated that the baseline ERC thickness, WBV, and volume of the hippocampus was not associated with cognitive decline measured using MMSE in control and MCI subjects, over a period of one year (Table 2, Figs. 2 and 3).

\section{DISCUSSION}

The main findings of the study were: (A) patients with mild to moderate AD had thinner ERC, smaller hippocampal volume, and WBV compared to subjects with MCI and NDC. Within the AD group, (B) baseline ERC and WBV were significantly associated with baseline cognition measured by MMSE and ADAScog and also with stage of dementia as measured by CDR sum of boxes scores. (C) Baseline ERC thickness but not hippocampal volume was associated with longitudinal changes in cognition over one year and could predict the degree of decline slopes as measured by MMSE and ADAS-cog. (D) Baseline WBV was also associated with greater subsequent cognitive decline measured with ADAS-cog, although the association with the MMSE was marginal. The models were controlled for age at baseline, education years, gender, cholinesterase inhibitors, center, and APOE genotype.

Reductions in the hippocampal and entorhinal regions between the $\mathrm{AD}$ and NDC in our study were similar to previous studies $[4,46]$. The differences in these regions between $\mathrm{MCI}$ and NDC were also 
comparable with a previous study [46]. We found greater reductions in hippocampus compared to ERC regions similar to these studies in both $\mathrm{AD}$ and $\mathrm{MCI}$ groups. However, the focuses of these studies were on predictors of $\mathrm{MCI}$ conversion to $\mathrm{AD}$, and they did not report on the association between the regions and the cognitive measures within the AD group.

Our findings are in line with previous studies that ERC measures correlate better with baseline cognitive scores than hippocampal volume and that atrophy in ERC predicts cognitive decline better than hippocampal atrophy [7, 11, 47-48]. Recently in a genome-wide study of atrophy in regions associated with neurodegeneration in $\mathrm{AD}$, we identified one single-nucleotide polymorphism (SNP) with a disease-specific effect associated with ERC volume in an intron of the ZNF292 gene (rs1925690) and an intergenic SNP, flanking the ARPP-21 gene, with an overall effect on entorhinal cortical thickness (rs11129640) [41]. Genewide scoring also highlighted PICALM as the most significant gene associated with ERC thickness [49].

Although we found that hippocampal volume associated with the baseline cognitive measures as previously reported $[8,50,51]$, we found no association between hippocampal volume and subsequent cognitive change, which has also been previously reported by some [52, 53], but not all authors [54]. Mungas and colleagues previously reported that hippocampal atrophy predicted decline in AD but only in those subjects without lacunes [12].

WBV correlated with baseline clinical measures and predicted future cognitive decline, which probably reflects the correspondence between these measures of overall cerebral loss and global cognitive measures in the moderate stages of $\mathrm{AD}$ as reported earlier $[52,55]$.

Structures within the temporal lobe have long been associated with $\mathrm{AD}$ decline because of their critical role in the formation of long-term memory, one of the first functions to be affected in disease progression [51]. Both ERC and hippocampus are essential parts of the medial temporal lobe system that supports declarative (conscious) memory [56]. AD pathology primarily begins in ERC, followed by immediate progression through subiculum to the hippocampus proper [5]. Pathologically, Braak and Braak demonstrated that the spread of neurofibrillary tangles in postmortem brains appear first in the prealpha transentorhinal neurons and then spread to the ERC proper [5]. Developmental, morphological, functional, and molecular features of layer II neurons in the ERC interact to promote early susceptibility of this cell type to aging and $\mathrm{AD}$ [57]. Within the ERC, there is subregional specificity for molecular alterations that may initiate cognitive decline and with a potential to directly contribute to downstream cascades in its primary afferent regions, the hippocampus [57]. Previous clinical studies demonstrated that the rates of cognitive decline accelerated with time in $\mathrm{AD}[58,59]$, suggesting accelerated neurodegeneration in AD. Both cross-sectional and serial MRI studies on patients with AD have consistently found volume losses in both ERC and hippocampus [48, 51, 60-64]. Taken together, these findings suggest that $\mathrm{AD}$ is associated with progressive atrophy of both ERC and hippocampus, providing potential surrogate markers for this disease. Assuming that degenerative processes proceed at similar rates in the ERC and hippocampus, one might therefore expect to find higher atrophy rates in the structure where neurodegeneration began earlier. Our results substantiate this hypothesis, which is consistent with the view of earlier involvement of AD pathology in the ERC than the hippocampus [65]. Risacher et al., however, have found similar atrophy rates of 4-5\% per year in the hippocampus and entorhinal cortex in the ADNI cohort [66].

APOE $\varepsilon 4$ had no influence on the relation between the ERC, hippocampal, and WBV with cognitive severity or cognitive decline in our study, similar to other reports $[67,68]$. We have previously reported that the homozygous $\varepsilon 4$ carriers had significant volume loss in hippocampus and amygdala in AD [43]. Possibly the influence is not seen due to lack of association of hippocampus volume with cognitive severity or longitudinal cognitive decline in AD. This warrants further evaluation in future longitudinal studies. We found significant correlations between structural MRI measures and baseline MMSE for healthy control subjects in our study, but the small range of MMSE for healthy subjects means that this finding should be viewed with some caution.

Strengths of the current study include the sample size and our use of automated MRI measures. The study compares cognitive decline for $\mathrm{AD}, \mathrm{MCI}$, and NDC subjects using the baseline brain measures as continuous variables and the quartiles for graphical view.

In conclusion, subjects with $\mathrm{AD}$ had thinner ERC, smaller WBV, and hippocampal volume compared to subjects with MCI and NDC. In addition, with in AD subjects, thinner ERC was associated with lower baseline cognitive scores, higher disease severity, and predicted greater subsequent cognitive decline at one year follow up. MRI is superior in defining disease stage clinically and has been shown to be a slightly 
better predictor of future clinical decline than cerebrospinal fluid biomarkers [69, 70]. Neuroimaging biomarkers that predict decline would have a great potential for increasing the efficacy of early intervention [71]. By focusing structural analyses on regions known to be first affected in $\mathrm{AD}$, we may better identify those individuals at greatest risk for future memory decline, valuable in determining the course of future care needed by these individuals, requiring more substantial care at an earlier time point.

\section{ACKNOWLEDGMENTS}

This study was supported by InnoMed (Innovative Medicines in Europe), an Integrated Project funded by the European Union of the Sixth Framework program priority FP6-2004-LIFESCIHEALTH-5, Life Sciences, Genomics and Biotechnology for Health. Thanks to the Strategic Research Programme in Neuroscience at Karolinska Institutet (StratNeuro). The authors are also grateful for funding from the National Institute of Health Research (NIHR) Biomedical Research Centre for Mental Health at the South London and Maudsley NHS Foundation Trust and King's College London and Alzheimer's Research UK. Authors' disclosures available online (http://www.jalz.com/disclosures/view.php?id=1504).

\section{REFERENCES}

[1] Ferri CP, Prince M, Brayne C, Brodaty H, Fratiglioni L, Ganguli M, Hall K, Hasegawa K, Hendrie H, Huang Y, Jorm A, Mathers C, Menezes PR, Rimmer E, Scazufca M, Alzheimer's Disease, International (2005) Global prevalence of dementia: A Delphi consensus study. Lancet 366, 2112-2117.

[2] Frank RA, Galasko D, Hampel H, Hardy J, de Leon MJ, Mehta PD, Rogers J, Siemers E, Trojanowski JQ, National Institute on Aging Biological Markers Working Group (2003) Biological markers for therapeutic trials in Alzheimer's disease. Proceedings of the biological markers working group; NIA initiative on neuroimaging in Alzheimer's disease. Neurobiol Aging 24, 521-536.

[3] Galasko D (2005) Biomarkers for Alzheimer's diseaseclinical needs and application. J Alzheimers Dis 8, 339-346.

[4] Fennema-Notestine C, McEvoy LK, Hagler DJ Jr, Jacobson MW, Dale AM, The Alzheimer's Disease Neuroimaging Initiative (2009) Structural neuroimaging in the detection and prognosis of pre-clinical and early AD. Behav Neurol 21, 3-12.

[5] Braak H, Braak E (1991) Neuropathological staging of Alzheimer-related changes. Acta Neuropathol 82, 239-259.

[6] Braak H, Alafuzoff I, Arzberger T, Kretzschmar H, Del Tredici K (2006) Staging of Alzheimer disease-associated neurofibrillary pathology using paraffin sections and immunocytochemistry. Acta Neuropathol 112, 389-404.
[7] Jack CR Jr, Shiung MM, Gunter JL, O'Brien PC, Weigand SD, Knopman DS, Boeve BF, Ivnik RJ, Smith GE, Cha RH, Tangalos EG, Petersen RC (2004) Comparison of different MRI brain atrophy rate measures with clinical disease progression in AD. Neurology 62, 591-600.

[8] Killiany RJ, Hyman BT, Gomez-Isla T, Moss MB, Kikinis R, Jolesz F, Tanzi R, Jones K, Albert MS (2002) MRI measures of entorhinal cortex vs hippocampus in preclinical AD. Neurology 58, 1188-1196.

[9] Varon D, Loewenstein DA, Potter E, Greig MT, Agron J, Shen Q, Zhao W, Celeste Ramirez M, Santos I, Barker W, Potter H, Duara R (2011) Minimal atrophy of the entorhinal cortex and hippocampus: Progression of cognitive impairment. Dement Geriatr Cogn Disord 31, 276-283.

[10] McEvoy LK, Fennema-Notestine C, Roddey JC, Hagler DJ Jr, Holland D, Karow DS, Pung CJ, Brewer JB, Dale AM, Alzheimer's Disease Neuroimaging Initiative (2009) Alzheimer disease: Quantitative structural neuroimaging for detection and prediction of clinical and structural changes in mild cognitive impairment. Radiology 251, 195-205.

[11] Cardenas VA, Chao LL, Studholme C, Yaffe K, Miller BL, Madison C, Buckley ST, Mungas D, Schuff N, Weiner MW (2011) Brain atrophy associated with baseline and longitudinal measures of cognition. Neurobiol Aging 32, 572-580.

[12] Mungas D, Jagust WJ, Reed BR, Kramer JH, Weiner MW, Schuff N, Norman D, Mack WJ, Willis L, Chui HC (2001) MRI predictors of cognition in subcortical ischemic vascular disease and Alzheimer's disease. Neurology 57, 22292235.

[13] Costafreda SG, Dinov ID, Tu Z, Shi Y, Liu CY, Kloszewska I, Mecocci P, Soininen H, Tsolaki M, Vellas B, Wahlund LO, Spenger C, Toga AW, Lovestone S, Simmons A (2011) Automated hippocampal shape analysis predicts the onset of dementia in mild cognitive impairment. Neuroimage 56, 212-219.

[14] Westman E, Simmons A, Zhang Y, Muehlboeck JS, Tunnard C, Liu Y, Collins L, Evans A, Mecocci P, Vellas B, Tsolaki M, Kłoszewska I, Soininen H, Lovestone S, Spenger C, Wahlund LO, AddNeuroMed consortium (2011) Multivariate analysis of MRI data for Alzheimer's disease, mild cognitive impairment and healthy controls. Neuroimage 54, 11781187.

[15] Liu Y, Paajanen T, Zhang Y, Westman E, Wahlund LO, Simmons A, Tunnard C, Sobow T, Mecocci P, Tsolaki M, Vellas B, Muehlboeck S, Evans A, Spenger C, Lovestone S, Soininen H, AddNeuroMed Consortium (2010) Analysis of regional MRI volumes and thicknesses as predictors of conversion from mild cognitive impairment to Alzheimer's disease. Neurobiol Aging 31, 1375-1385.

[16] Westman E, Simmons A, Muehlboeck JS, Mecocci P, Vellas B, Tsolaki MM, Kloszewska I, Soininen H, Weiner MW, Lovestone S, Spenger C, Wahlund LO (2011) AddNeuroMed and ADNI: Similar patterns of Alzheimer's atrophy and automated MRI classification accuracy in Europe and North America. Neuroimage 58, 818-828.

[17] Westman E, Cavallin L, Muehlboeck JS, Zhang Y, Mecocci P, Vellas B, Tsolaki M, Kloszewska I, Soininen H, Spenger C, Lovestone S, Simmons A, Wahlund LO (2011) Sensitivity and specificity of medial temporal lobe visual ratings and multivariate regional MRI classification in Alzheimer's disease. PLoS One 6, e22506.

[18] Liu Y, Paajanen T, Zhang Y, Westman E, Wahlund LO, Simmons A, Tunnard C, Sobow T, Mecocci P, Tsolaki M, Vellas B, Muehlboeck S, Evans A, Spenger C, Lovestone S, Soininen H, AddNeuroMed Consortium (2011) Combination analysis 
of neuropsychological tests and structural MRI measures in differentiating $\mathrm{AD}, \mathrm{MCI}$ and control groups - the AddNeuroMed study. Neurobiol Aging 32, 1198-1206.

[19] Lovestone S, Francis P, Strandgaard K (2007) Biomarkers for disease modification trials-the innovative medicines initiative and AddNeuroMed. J Nutr Health Aging 11, 359-361.

[20] McKhann G, Drachman D, Folstein M, Katzman R, Price D, Stadlan EM (1984) Clinical diagnosis of Alzheimer's disease: Report of the NINCDS-ADRDA Work Group under the auspices of Department of Health and Human Services Task Force on Alzheimer's disease. Neurology 34, 939-944.

[21] Folstein MF, Folstein SE, McHugh PR (1975) 'Mini-mental state': A practical method for grading the cognitive state of patients for the clinician. J Psychiatr Res 12, 189-198.

[22] Hughes CP, Berg L, Danziger WL, Coben LA, Martin RL (1982) A new clinical scale for the staging of dementia. $\mathrm{Br} \mathrm{J}$ Psychiatry 140, 566-572.

[23] Simmons A, Westman E, Muehlboeck S, Mecocci P, Vellas B, Tsolaki M, Kłoszewska I, Wahlund LO, Soininen H, Lovestone S, Evans A, Spenger C (2011) The AddNeuroMed framework for multi-centre MRI assessment of Alzheimer's disease: Experience from the first 24 months. Int J Ger Psych 26, 75-82.

[24] Thambisetty M, Simmons A, Velayudhan L, Hye A, Campbell J, Zhang Y, Wahlund LO, Westman E, Kinsey A, Güntert A, Proitsi P, Powell J, Causevic M, Killick R, Lunnon K, Lynham S, Broadstock M, Choudhry F, Howlett DR, Williams RJ, Sharp SI, Mitchelmore C, Tunnard C, Leung R, Foy C, O'Brien D, Breen G, Furney SJ, Ward M, Kloszewska I, Mecocci P, Soininen H, Tsolaki M, Vellas B, Hodges A, Murphy DG, Parkins S, Richardson JC, Resnick SM, Ferrucci L, Wong DF, Zhou Y, Muehlboeck S, Evans A, Francis PT, Spenger C, Lovestone S (2010) Association of plasma clusterin concentration with severity, pathology, and progression in Alzheimer disease. Arch Gen Psych 67, 739-748.

[25] Roth M, Tym E, Mountjoy CQ, Huppert FA, Hendrie H, Verma S, Goddard R (1986) CAMDEX. A standardised instrument for the diagnosis of mental disorder in the elderly with special reference to the early detection of dementia. $\mathrm{Br}$ J Psychiatry 149, 698-709.

[26] Rosen WG, Mohs RC, Davis KL (1984) A new rating scale for Alzheimer's disease. Am J Psychiatry 141, 13561364.

[27] Wenham PR, Price WH, Blandell G (1991) Apolipoprotein E genotyping by one-stage PCR. Lancet 337, 11581159.

[28] Jack CR Jr, Bernstein MA, Fox NC, Thompson P, Alexander G, Harvey D, Borowski B, Britson PJ, Whitwell Jennifer L, Ward C, Dale AM, Felmlee JP, Gunter JL, Hill DL, Killiany R, Schuff N, Fox-Bosetti S, Lin C, Studholme C, DeCarli CS, Krueger G, Ward HA, Metzger GJ, Scott KT, Mallozzi R, Blezek D, Levy J, Debbins JP, Fleisher AS, Albert M, Green R, Bartzokis G, Glover G, Mugler J, Weiner MW (2008) The Alzheimer's Disease Neuroimaging Initiative (ADNI): MRI methods. J Magn Reson Imaging 27, 685-691.

[29] Simmons A, Westman E, Muehlboeck S, Mecocci P, Vellas B, Tsolaki M, Kłoszewska I, Wahlund LO, Soininen H, Lovestone S, Evans A, Spenger C, AddNeuroMed Consortium (2009) MRI measures of Alzheimer's disease and the AddNeuroMed study. Ann N Y Acad Sci 1180, 47-55.

[30] Segonne F, Dale AM, Busa E, Glessner M, Salat D, Hahn HK, Fischl B (2004) A hybrid approach to the skull stripping problem in MRI. Neuroimage 22, 1060-1075.

[31] Fischl B, Salat DH, Busa E, Albert M, Dieterich M, Haselgrove C, van der Kouwe A, Killiany R, Kennedy D, Klaveness
S, Montillo A, Makris N, Rosen B, Dale AM (2002) Whole brain segmentation: Automated labeling of neuroanatomical structures in the human brain. Neuron 33, 341-355.

[32] Fischl B, Salat DH, van der Kouwe AJ, Makris N, Segonne F, Quinn BT, Dale AM (2004) Sequence-independent segmentation of magnetic resonance images. Neuroimage 23(Suppl 1), S69-S84.

[33] Sled JG, Zijdenbos AP, Evans AC (1998) A nonparametric method for automatic correction of intensity nonuniformity in MRI data. IEEE Trans Med Imaging 17, 87-97.

[34] Fischl B, Liu A, Dale AM (2001) Automated manifold surgery: Constructing geometrically accurate and topologically correct models of the human cerebral cortex. IEEE Trans Med Imaging 20, 70-80.

[35] Segonne F, Pacheco J, Fischl B (2007) Geometrically accurate topology-correction of cortical surfaces using nonseparating loops. IEEE Trans Med Imaging 26, 518-529.

[36] Dale AM, Fischl B, Sereno MI (1999) Cortical surface-based analysis. I. Segmentation and surface reconstruction. Neuroimage $\mathbf{9}, 179-194$.

[37] Dale AM, Sereno MI (1993) Improved localization of cortical activity by combining EEG and MEG with MRI cortical surface reconstruction: A linear approach. J Cogn Neurosci 5, 162-176.

[38] Fischl B, Dale AM (2000) Measuring the thickness of the human cerebral cortex from magnetic resonance images. Proc Natl Acad Sci U S A 97, 11050-11055.

[39] Fischl B, Sereno MI, Tootell RB, Dale AM (1999) Highresolution intersubject averaging and a coordinate system for the cortical surface. Hum Brain Mapp 8, 272-284.

[40] Desikan RS, Ségonne F, Fischl B, Quinn BT, Dickerson BC, Blacker D, Buckner RL, Dale AM, Maguire RP, Hyman BT, Albert MS, Killiany RJ (2006) An automated labeling system for subdividing the human cerebral cortex on MRI scans into gyral based regions of interest. Neuroimage 31, 968-980.

[41] Fischl B, van der Kouwe A, Destrieux C, Halgren E, Segonne F, Salat DH, Busa E, Seidman LJ, Goldstein J, Kennedy D, Caviness V, Makris N, Rosen B, Dale AM (2004) Automatically parcellating the human cerebral cortex. Cereb Cortex 14, 11-22.

[42] Westman E, Wahlund LO, Foy C, Poppe M, Cooper A, Murphy D, Spenger C, Lovestone S, Simmons A (2010) Combining MRI and MRS to distinguish between Alzheimer's disease and healthy controls. J Alzheimers Dis 22, 171181.

[43] Liu Y, Paajanen T, Westman E, Wahlund LO, Simmons A, Tunnard C, Sobow T, Proitsi P, Powell J, Mecocci P, Tsolaki M, Vellas B, Muehlboeck S, Evans A, Spenger C, Lovestone S, Soininen H, AddNeuroMed Consortium (2010) Effect of APOE epsilon4 allele on cortical thicknesses and volumes: The AddNeuroMed study. J Alzheimers Dis 21, 947966.

[44] Liu Y, Paajanen T, Westman E, Zhang Y, Wahlund LO, Simmons A, Tunnard C, Sobow T, Proitsi P, Powell J, Mecocci P, Tsolaki M, Vellas B, Muehlboeck S, Evans A, Spenger C, Lovestone S, Soininen H, AddNeuroMed Consortium (2010) APOE epsilon2 allele is associated with larger regional cortical thicknesses and volumes. Dement Geriatr Cogn Disord 30, 229-237.

[45] Westman E, Aguilar C, Muehlboeck J-S, Simmons A (2012) Regional magnetic resonance imaging measures for multivariate analysis in Alzheimer's disease and mild cognitive impairment. Brain Topography, doi: 10.1007/s10548-0120246-x [Epub ahead of print] 
[46] Karow DS, McEvoy LK, Fennema-Notestine C, Hagler DJ Jr, Jennings RG, Brewer JB, Hoh CK, Dale AM, Alzheimer's Disease Neuroimaging Initiative (2010) Relative capability of MR imaging and FDG PET to depict changes associated with prodromal and early Alzheimer disease. Radiology 256, 932-942.

[47] Burggren AC, Renner B, Jones M, Donix M, Suthana NA, Martin-Harris L, Ercoli LM, Miller KJ, Siddarth P, Small GW, Bookheimer SY (2011) Thickness in entorhinal and subicular cortex predicts episodic memory decline in mild cognitive impairment. Int J Alzheimers Dis 15, 956053.

[48] Du AT, Schuff N, Kramer JH, Ganzer S, Zhu XP, Jagust WJ Miller BL, Reed BR, Mungas D, Yaffe K, Chui HC, Weiner MW (2004) Higher atrophy rate of entorhinal cortex than hippocampus in AD. Neurology 62, 422-427.

[49] Furney SJ, Simmons A, Breen G, Pedroso I, Lunnon K, Proitsi P, Hodges A, Powell J, Wahlund LO, Kloszewska I, Mecocci P, Soininen H, Tsolaki M, Vellas B, Spenger C, Lathrop M, Shen L, Kim S, Saykin AJ, Weiner MW, Lovestone S; Alzheimer's Disease Neuroimaging Initiative; AddNeuroMed Consortium (2011) Genome-wide association with MRI atrophy measures as a quantitative trait locus for Alzheimer's disease. Mol Psychiatry 16, 1130-1138.

[50] Morra JH, Tu Z, Apostolova LG, Green AE, Avedissian C, Madsen SK et al. Parikshak N, Toga AW, Jack CR Jr, Schuff N, Weiner MW, Thompson PM, Alzheimer's Disease Neuroimaging Initiative (2009) Automated mapping of hippocampal atrophy in 1-year repeat MRI data from 490 subjects with Alzheimer's disease, mild cognitive impairment, and elderly controls. Neuroimage 45(1 Suppl), S3-S15.

[51] Weiner MW, Veitch DP, Aisen PS, Beckett LA, Cairns NJ, Green RC, Harvey D, Jack CR, Jagust W, Liu E, Morris JC, Petersen RC, Saykin AJ, Schmidt ME, Shaw L, Siuciak JA, Soares H, Toga AW, Trojanowski JQ, Alzheimer's Disease Neuroimaging Initiative (2011) The Alzheimer's Disease Neuroimaging Initiative: A review of papers published since its inception. Alzheimers Dement 8(1 Suppl), S1-S68.

[52] Ridha BH, Anderson VM, Barnes J, Boyes RG, Price SL, Rossor MN, Whitwell JL, Jenkins L, Black RS, Grundman M, Fox NC (2008) Volumetric MRI and cognitive measures in Alzheimer disease: Comparison of markers of progression. J Neurol 255, 567-574.

[53] Morra JH, Tu Z, Apostolova LG, Green AE, Avedissian C, Madsen SK, Parikshak N, Hua X, Toga AW, Jack CR Jr, Schuff N, Weiner MW, Thompson PM, Alzheimer's Disease Neuroimaging Initiative (2009) Automated 3D mapping of hippocampal atrophy and its clinical correlates in 400 subjects with Alzheimer's disease, mild cognitive impairment, and elderly controls. Hum Brain Mapp 30, 27662788.

[54] Kovacevic S, Rafii MS, Brewer JB, Alzheimer's Disease Neuroimaging Initiative (2009) High throughput, fully automated volumetry for prediction of MMSE and CDR decline in mild cognitive impairment. Alzheimer Dis Assoc Disorder 23, 139145.

[55] Sluimer JD, van der Flier WM, Karas GB, Fox NC, Scheltens P, Barkhof F, Vrenken H (2008) Whole-brain atrophy rate and cognitive decline: Longitudinal MR study of memory clinic patients. Radiology 248, 590-598.

[56] Squire LR, Zola-Morgan S (1991) The medial temporal lobe memory system. Science 253, 1380-1386.

[57] Stranahan AM, Mattson MP (2010) Selective vulnerability of neurons in layer II of the entorhinal cortex during aging and Alzheimer's disease. Neural Plast 2010, 108190.
[58] Galasko DR, Gould RL, Abramson IS, Salmon DP (2000) Measuring cognitive change in a cohort of patients with Alzheimer's disease. Stat Med 19, 1421-1432.

[59] Suh GH, Ju YS, Yeon BK, Shah A (2004) A longitudinal study of Alzheimer's disease: Rates of cognitive and functional decline. Int J Geriatr Psychiatry 19, 817-824.

[60] Bobinski M, de Leon MJ, Convit A, De Santi S, Wegiel J, Tarshish CY, Saint Louis LA, Wisniewski HM (1999) MRI of entorhinal cortex in mild Alzheimer's disease. Lancet 353, 38-40.

[61] Juottonen K, Laakso MP, Insausti R, Lehtovirta M, Pitkänen A, Partanen K, Soininen H (1998) Volumes of the entorhinal and perirhinal cortices in Alzheimer's disease. Neurobiol Aging 19, 15-22.

[62] Dickerson BC, Goncharova I, Sullivan MP, Forchetti C, Wilson RS, Bennett DA, Beckett LA, deToledo-Morrell L (2001) MRI-derived entorhinal and hippocampal atrophy in incipient and very mild Alzheimer's disease. Neurobiol Aging 22, 747-754.

[63] Du AT, Schuff N, Amend D, Laakso MP, Hsu YY, Jagust WJ, Yaffe K, Kramer JH, Reed B, Norman D, Chui HC, Weiner MW (2001) Magnetic resonance imaging of the entorhinal cortex and hippocampus in mild cognitive impairment and Alzheimer's disease. J Neurol Neurosurg Psychiatry 71, 441447.

[64] Jack CR Jr (2011) Alliance for Aging Research AD Biomarkers Work Group: Structural MRI. Neurobiol Aging 32(Suppl 1), S48-S57.

[65] Braak H, Braak E (1995) Staging of Alzheimer's diseaserelated neurofibrillary changes. Neurobiol Aging 16, 271-278, discussion 278-284.

[66] Risacher SL, Shen L, West JD, Kim S, McDonald BC, Beckett LA, Harvey DJ, Jack CR, Weiner MW, Saykin AJ, Alzheimer's Disease Neuroimaging Initiative (ADNI) (2010) Longitudinal MRI atrophy biomarkers: Relationship to conversion in the ADNI cohort. Neurobiol Aging 31, 14011418 .

[67] Thompson WK, Hallmayer J, O’Hara R, Alzheimer's Disease Neuroimaging Initiative (2011) Design considerations for characterizing psychiatric trajectories across the lifespan: Application to effects of APOE- $\varepsilon 4$ on cerebral cortical thickness in Alzheimer's disease. Am J Psychiatry 168, 894-903.

[68] Wang PN, Liu HC, Lirng JF, Lin KN, Wu ZA (2009) Accelerated hippocampal atrophy rates in stable and progressive amnestic mild cognitive impairment. Psychiatry Res 171, 221231.

[69] Vemuri P, Wiste HJ, Weigand SD, Shaw LM, Trojanowski JQ, Weiner MW, Knopman DS, Petersen RC, Jack CR Jr, Alzheimer's Disease Neuroimaging Initiative (2009) MRI and CSF biomarkers in normal, MCI, and AD subjects: Predicting future clinical change. Neurology 73, 294301.

[70] Vemuri P, Wiste HJ, Weigand SD, Shaw LM, Trojanowski JQ, Weiner MW, Knopman DS, Petersen RC, Jack CR Jr, Alzheimer's Disease Neuroimaging Initiative (2009) MRI and CSF biomarkers in normal, MCI, and AD subjects: Diagnostic discrimination and cognitive correlations. Neurology 73, 287293.

[71] Jack CR Jr, Knopman DS, Jagust WJ, Shaw LM, Aisen PS, Weiner MW, Petersen RC, Trojanowski JQ (2010) Hypothetical model of dynamic biomarkers of the Alzheimer's pathological cascade. Lancet Neurol 9, 119-128.

[72] Westman E, Wahlund LO, Foy C, Poppe M, Cooper A, Murphy D, Spenger C, Lovestone S, Simmons A (2011) Magnetic 
resonance imaging and magnetic resonance spectroscopy for detection of early Alzheimer's disease. J Alzheimer's Disease 26, 307-319.

[73] Thambisetty M, Simmons A, Hye A, Campbell J, Zhang Y, Wahlund L-O, Kinsey A, Causevic M, Killick R, Broadstock M, Tunnard C, Leung R, Foy C, O'Brien D, Prinz T, Ward M, Kloszewska I, Mecozzi P, Soininen H, Tsolaki M, Vellas B, Murphy D, Parkins S, Muehlboeck S, Evans A, Francis P, Spenger C, Lovestone $S$ for the AddNeuroMed consortium
(2011) Plasma biomarkers of brain atrophy in Alzheimer's disease. PLoS One 6, e28527.

[74] Kiddle SJ, Thambisetty M, Simmons A, Riddoch-Contreras J, Hye A, Westman E, Pike I, Ward M, Johnston C, Lupton MK, Lunnon K, Soininen H, Klosweska I, Tsolaki M, Vellas B, Mecocci P, Lovestone S, Newhouse S, Dobson R (2012) Plasma based markers of [11C]-PiB brain amyloid burden. PLoS One 7, e44260. 